\title{
An Analysis of the Stability of Monetary Aggragates in Botswana
}

\section{Lesego Sekwati ${ }^{1}$}

\begin{abstract}
This paper seeks to investigate whether M1, M2 and M3 monetary aggregates in Botswana exhibit stability characteristics. Stability of the concerned aggregate implies it has a predictable path and therefore may be used by the authority in making policy decisions. This is achieved by employing stationarity tests and cointegration techniques to monthly data on these aggregates. The results indicate a stable relationship for M2 and M3 aggregates but not for M1, suggesting that M2 and M3 may be used as targets of monetary policy. Although formal tests of convergence on M2 and M3 were not employed, the fact that M3 is made up of Bank of Botswana Certificates among others. It seems reasonable to assume that M3 would be a better target than M2. A potential area for further research may be to assess whether using either of these monetary aggregates to anchor policy would actually work for Botswana, given also the existing trade ties and the exchange rate regime.
\end{abstract}

\section{Introduction}

In policy regimes based on monetary targeting, as is the case with Botswana, authorities choose a quantity they wish to control in order to achieve their inflation objectives. These quantities can be any of money supply, monetary base, credit expansion, etc. The Bank of Botswana, in the conduct of monetary policy focuses on domestic credit expansion, that is, the rate of growth of commercial bank credit to the private sector, and growth in government expenditure to control inflation (Bank of Botswana, 2008). This study, although not intended to assess the efficacy of this strategy seeks to investigate whether the money supply, conceptualizsed in either of these forms - M1, M2 or M3 may also be used to anchor monetary policy in Botswana. Several arguments have been used to support the idea of using the money supply, or more precisely the rate of change of money supply as a target for monetary policy. It is argued that monetary policy cannot be used to influence real magnitudes but only nominal ones such as the price level and nominal national income (Pierce and Tysome, 1985). The demand for money has particularly been used to support the links between money supply and nominal goals of monetary policy, so that as long as demand for money exists, then with inflationary expectations, a determinate rate of inflation will emerge only if there is control over the money supply. In this paper therefore, we investigate whether money supply may also be used as a target

$1^{*}$ Lesego Sekwati is a Lecturer in the Department of Economics, University of Botswana, Private Bag 00705, Gaborone, Botswana. Tel: +267 355 5092. Email:sekwati@mopipi. ub.bw. The author acknowledges reviewer's comments. All other errors and omissions remain those of the author. 
for monetary policy. If the money supply is to be used to anchor monetary policy however, the authorities must decide which of the monetary aggregates (M1, M2 or M3) will be accorded primary importance.

Three criteria are usually used to evaluate the suitability of an aggregate: (i) the closeness and stability of the relationship between changes in the monetary aggregate and changes in the goal variables (ii) the controllability of the aggregate (iii) and its measurability. While M1 is considered to have a more stable demand function than broader monetary aggregates because of its narrowness, it is at risk of Goodhart's law (ibid). M2 is sometimes also regarded as too narrow an aggregate upon which to target monetary policy. In many cases, M3 is regarded as having an advantage considering its controllability and measurability because it is usually linked to changes in key credit components such as bank lending, government debt sales, domestic credit expansion. etc. In this paper, we employ cointegration techniques to investigate whether any of the three categorisations of money supply (M1, M2 or M3), exhibit stability characteristics. Other things being equal, stability of the monetary aggregate would imply predictability, and therefore controllability, which are essential in determining a target for monetary policy. The conclusions drawn from this analysis and the implications thereof are limited by the method of analysis employed in the study. The conclusions are therefore solely based on whether these aggregates exhibit stable characteristics.

The rest of the paper is structured as follows: In Section II, we review the strategy employed by Bank of Botswana to control inflation in Botswana. Section III outlines the money multiplier model of money supply, while Section IV outlines the method of analysis. In Section V, we discuss the results of the estimation including policy implications, while Section VI presents the conclusions deriving from the analysis.

\section{Inflation Control in Botswana}

In this section, we review the Bank of Botswana's strategy for controlling inflation. Botswana is one of the countries still practicing monetary targeting instead of inflation targeting. Monetary targeting comprises three key elements: (1) reliance on information conveyed by a monetary aggregate to conduct monetary policy; (2) announcement of targets for monetary aggregates; and (3) some accountability mechanism to preclude large and systematic deviations from the monetary targets (Mishkin, 2000). Inflation targeting on the other hand involves five key elements: (1) public announcement of medium term numerical targets for inflation; (2) an institutional commitment to price stability as the primary long run goal of monetary policy and a commitment to achieve the inflation goal; (3) an information inclusive strategy in which many variables and not just monetary aggregates are used in making decisions about monetary policy; (4) increased transparency of the monetary policy strategy through communication with the public and markets about the plans and objectives of monetary policy makers; and (5) increased accountability of the central bank for attaining its inflation objective (ibid).

With the problems encountered (instability of the relationship between monetary aggregates among others) with monetary targeting in the 1970s and 1980s, inflation 
targeting was adopted in a number of industrialised countries in the 1990s, such as New Zealand, Canada, Israel, the United Kingdom, Sweden, etc. After adopting inflation targeting these countries experienced significant reductions in the inflation rate (ibid). The experiences of Germany and Switzerland have shown however, that monetary targeting can work just as well if it is actively used to clearly communicate a long run strategy of inflation control. It has been found also that monetary targeting is flexible in practice allowing the authority to also address financial instability and output fluctuations as well.

Botswana has over the years practiced monetary targeting where domestic credit expansion has been used as a target for monetary policy. Credit growth is regarded by the Bank as a useful indicator of demand conditions and the potential impact on inflation. It is important to note here that the objective of the Bank's monetary policy is to achieve a sustainable, low and predictable level of inflation (Bank of Botswana, 2008). This objective is achieved by using interest rates and open market operations (OMO) to affect demand conditions in the economy and ultimately the rate of price changes (ibid). The Bank, though it acknowledges that the rate of growth of credit is not an optimal measure of demand conditions in the economy, has over the years provided useful information in this regard. Every year the Bank publishes a monetary policy statement, which in addition to announcing an inflation objective also explains the policy horizon for which the inflation objective is set, and the policy measures that will be needed to achieve it (BoB 2008). In publishing the monetary policy statement, the Bank also fulfills its obligation of accountability and transparency.

Figure 1 (in the Appendix) shows the inflationary trend between 2000 and 2007. Save for the spikes noticeable in 2003 and 2006, inflation in Botswana has remained relatively stable over this period (see also Chakrabati 2006). Over this period however, the Bank has more often than not failed to achieve its annual inflation objectives. Over the last 5 years (2002-2007), the Bank's annual inflation objectives have been set at 4-7 percent for 2004-2007, and 4-6 percent for 2000 2003 (Bank of Botswana, 2003-2008). Except for 2004 however, the annual inflation has been falling outside the Bank's objectives, with 7.1 percent recorded for 2007; 11.6 percent in 2006; 8.6 percent in 2005; 7.0 percent in 2004; 9.2 percent in 2003 and 8.0 percent in 2002 (ibid). In 2008 however, the Bank announced a medium term objective arguing that price stability can only be realistically achieved in the medium term. An important policy question however, concerns whether the Bank's chosen target of policy, that is, the domestic credit expansion is indeed the right target. Should the Bank continue targeting domestic credit expansion, or some other target? The purpose of this article is to assess whether M1, M2 and M3 monetary aggregates exhibit stability characteristics, and may therefore be potential targets of policy or not. The study is motivated by the Bank's continued failure to meet annual inflation objectives perhaps necessitates further research into alternative monetary policy targets.

The objective of the exchange rate policy in Botswana is to stabilise the exchange rate in relation to main trading partners. Maintaining stability, real pula exchange rate is consistent with achieving the Bank's inflation objective. Botswana operates 
a crawling peg exchange rate regime, where the Pula is pegged to a trade weighted basket of currencies reflecting the country's major trading partners so as to smooth exchange rate fluctuations among the trading partners. The basket consists of the South African Rand and the Special Drawing Right (SDR), with the South African Rand having a greater share in the basket given the close trade ties between Botswana and South Africa. As a result of the ties between Botswana and South Africa, South African prices have over the years had a strong influence on prices in Botswana.

\section{The Multiplier Model Of Money Supply}

The multiplier model of money supply, originally developed by Brunner (1961) and Brunner and Meltzer (1964) has become the standard paradigm in macroeconomics to explain how policy actions of the central bank influence the money stock (Garfield and Thornton 1991). In constructing the model, we define the money supply (Ms) to include the cash held by the non bank private sector $(\mathrm{C})$ and deposits of the banking system (D), so that

$$
\mathrm{Ms}=\mathrm{C}+\mathrm{D}
$$

High powered money, or the monetary base (B) is defined as the net liabilities of the central bank held either by the non bank private sector (RP) or the banks (RB), so that

$$
\mathrm{B}=\mathrm{RP}+\mathrm{RB}
$$

Multiplying both sides of equation (1) by B/ (RP + RB), yields

$$
\mathrm{Ms}=[(\mathrm{C}+\mathrm{D}) /(\mathrm{RP}+\mathrm{RB})]^{*} \mathrm{~B}
$$

and further multiplying both the numerator and the denominator of the term in square brackets by $1 / \mathrm{D}$ then yields;

$$
\mathrm{Ms}=[(1+(\mathrm{C} / \mathrm{D})) /((\mathrm{RP} / \mathrm{D})+(\mathrm{RB} / \mathrm{D}))]^{* \mathrm{~B}}
$$

This simplifies to

$$
\begin{aligned}
& \mathrm{Ms}=[(1+\mathrm{c}) /(\mathrm{p}+\mathrm{b})]^{*} \mathrm{~B} \\
& \mathrm{Ms}=\mathrm{k} * \mathrm{~B} \quad ; \mathrm{k}=1+\mathrm{c} / \mathrm{p}+\mathrm{b}
\end{aligned}
$$

Where: $\quad \mathrm{c}$ is the ratio of cash to deposits

$\mathrm{p}$ indicates the reserves to deposit ratio of non bank private sector

$\mathrm{b}$ indicates the reserve assets to deposit ratio of the commercial banks

$\mathrm{k}$ is the money multiplier, so that changes in the money

supply are a product of changes in the base B and in the value of the multiplier $\mathrm{k}$.

By rearranging the identity $\mathrm{Ms}=\mathrm{k} * \mathrm{~B}$, a monetary aggregate can then be defined as

$$
\mathrm{Ms}_{\mathrm{i}}=\mathrm{k}_{\mathrm{i}}+\mathrm{B}
$$

Where $\mathrm{Ms}_{\mathrm{i}}$ is the log of money supply, $\mathrm{B}$ is the $\log$ of the monetary base, and $\mathrm{k}_{\mathrm{i}}$ is the $\log$ of the money multiplier. 


\section{Methodology}

This study employs stationarity and cointegration tests to assess the stability of M1, M2 and M3 monetary aggregates in Botswana. A popular test of the stationarity of time series data is the unit root test in which the null hypothesis of unit root (implying the series is non stationary) is tested against an alternative that the root is less than one. A series is said to be stationary if it fluctuates around a constant long run mean (Enders, 1995). Assuming that a variable $y_{t}$ is generated by the first order autoregressive AR (1) process

$$
\mathrm{y}_{\mathrm{t}}=\rho \mathrm{y}_{\mathrm{t}-1}+\mathrm{x}_{\mathrm{t}} \delta+\mathrm{u}_{\mathrm{t}}
$$

where $x_{t}$ represents optional exogenous regressors such as a constant, or a constant and a trend, and $\rho$ and $\delta$ are the parameters to be estimated, and $u_{t}$ is the disturbance term. If $|r| \geq 1$ then $y$ is a non stationary series, implying that there is no long run mean to which the series reverts. If $|r|<1$ however, then y is a stationary series. In stationarity tests therefore, we test whether the absolute value of $\rho$ is absolutely less than one indicating mean reversion. The null hypothesis is that $\mathrm{y}_{\mathrm{t}}$ has a unit root:

$\mathrm{H}_{0}: \rho=1$

Against the alternative that

$\mathrm{H}_{1}: \rho<1$

A convenient equation for carrying out the unit root test is to subtract $\mathrm{y}_{\mathrm{t}-1}$ on both sides of equation (8), and to define $\alpha=\rho-1$

$$
\Delta \mathrm{y}_{\mathrm{t}}=\alpha \mathrm{y}_{\mathrm{t}-1}+\mathrm{x}_{\mathrm{t}} \delta+\mathrm{u}_{\mathrm{t}}
$$

This allows us to test the null hypothesis $\mathrm{H}_{0}: \alpha=0$, against the alternative $\mathrm{H}_{1}<0$. The problem under $\mathrm{H}_{0}$ however is that $\mathrm{y}_{\mathrm{t}-1}$ is $\mathrm{I}(1)$, and so the usual central limit theorem that underlies the asymptotic standard normal distribution for the $t$ statistic does not apply: the $t$ statistic does not have an approximate standard normal distribution even in large samples (Wooldridge, 2006). The asymptotic distribution of the $t$ statistic under $\mathrm{H}_{0}$ has come to be known as the Dickey Fuller Distribution, after Dickey Fuller 1979. The resulting test for unit root is known as the Dickey Fuller (DF) test. It is important to note however, that the DF unit root test assumes that the error terms are independently and identically distributed (Gujarati, 2003). The Augmented Dickey Fuller (ADF) test adjusts the DF test to take care of possible serial correlation by adding lagged terms of the regressand such that the y series follows an $\operatorname{AR}(p)$ process, i.e.

$$
\Delta \mathrm{y}_{\mathrm{t}}=\alpha \mathrm{y}_{\mathrm{t}-1}+\mathrm{x}_{\mathrm{t}} \delta+\psi_{1} \Delta \mathrm{y}_{\mathrm{t}-1}+\psi_{2} \Delta \mathrm{y}_{\mathrm{t}-2}+\ldots \Psi_{\mathrm{p}} \Delta \mathrm{y}_{\mathrm{t}-\mathrm{p}}+\mathrm{u}_{\mathrm{t}}
$$

To test the null hypothesis, we run the regression of $\Delta \mathrm{y}_{\mathrm{t}}$ on yt-1, $\Delta \mathrm{y}_{\mathrm{t}-1}, \ldots, \Delta \mathrm{y}_{\mathrm{t}-\mathrm{p}}$ And carry out the $t$ test as before. Note that the inclusion of lagged changes is intended to clean up any serial correlation in $\Delta \mathrm{y}_{\mathrm{t}}$. The lag length is however dictated by the frequency of the data (ibid). In this analysis, we add a sufficient number of lags to achieve this purpose. The results of the ADF tests, obtained using EVIEWS Version 3.1 are discussed in the next section. An alternative approach to the ADF tests of stationarity (also used in this analysis) is the approach suggested by Phillips (1987) and extended by Perron in (1988) and Phillips and Perron (1988). The 
Phillips Perron (PP) is a non parametric correction to the $t$ test (Harris, 1995). The PP method estimates the non augmented DF equation and modifies the $t$ ratio of the $\alpha$ coefficient so that serial correlation does not affect the asymptotic distribution of the test statistic. The asymptotic distribution of the PP modified $t$ ratio is the same as that of the ADF statistic (Gujarati, 2003). The results of the PP tests are also discussed in the next section.

The second stage of the analysis involved carrying out cointegration tests using the method developed by Johansen and Juselius (1990) between the monetary aggregates concerned (M1, M2, M3 and the Reserve Money, used as the Monetary Base in this study). Assuming a vector $Z_{t}$ of non stationary $I(1)$ variables, $A_{i}$ an (nxn) matrix of parameters, and $U_{t}$ a vector of innovations, we can specify a VAR of order $\mathrm{p}$ such that

$$
\mathrm{Z}_{\mathrm{t}}=\mathrm{A}_{1} \mathrm{Z}_{\mathrm{t}-1}+\ldots \ldots \ldots+\mathrm{A}_{\mathrm{k}} \mathrm{Z}_{\mathrm{t}-\mathrm{k}}+\mathrm{U}_{\mathrm{t}} \quad \mathrm{U}_{\mathrm{t}} \sim \mathrm{IN}(0, \Sigma)
$$

Equation (10) can be reformulated into a Vector Error Correction form such that

$$
\Delta \mathrm{Z}_{\mathrm{t}}=\Gamma_{1} \Delta \mathrm{Z}_{\mathrm{t}-1}+\ldots \ldots \ldots \Gamma_{\mathrm{k}-1} \Delta \mathrm{Z}_{\mathrm{t}-\mathrm{k}+1}+\Pi \mathrm{Z}_{\mathrm{t}-\mathrm{k}}+\mathrm{U}_{\mathrm{t}}
$$

Where $\Gamma_{i}=-\left(I-A_{1}-\ldots-A_{i}\right),(i=1, \ldots ., k-1)$ and $\Pi=-\left(I-A_{i}-\ldots .-A_{k}\right)$

This way of specifying the system contains information on both the short and long run adjustment to changes in $Z_{t}$, via the estimates of $\Gamma$ and $\Pi$, respectively. $\Pi=\alpha \beta$ where $\alpha$ represents the speed of adjustment to equilibrium, while $\beta$ is the matrix of long run coefficients such that the term $\beta^{`} Z_{t-k}$ embedded in equation (11) represents up to (n-1) cointegration relationships in the multivariate model which ensure that the $Z_{t}$ converge to their long run steady state solutions. Assuming $Z_{t}$ is a vector of non stationary $\mathrm{I}(1)$ variables, then all the terms in equation (10) which involve $\Delta Z_{t-i}$ are $\mathrm{I}(0)$ while $\Pi Z_{t-\mathrm{k}}$ must also be stationary for $\mathrm{U}_{t} \sim \mathrm{I}(0)$ to be white noise (Harris 1995). Harris (1995) argues that there are three instances when this requirement that $\Pi Z_{\mathrm{t}-\mathrm{k}} \sim \mathrm{I}(0)$ is met. First when all the variables in $\mathrm{Z}_{\mathrm{t}}$ are stationary and the appropriate modeling strategy would be to estimate the standard Sims type VAR in levels. Second when there is no cointegration at all, implying that there are no linear combinations of the $Z_{t}$ that are $I(0)$ and consequently $\Pi$ is an (nxn) matrix of zeros, such that the appropriate model to use is a VAR in first differences involving no long run elements; third is when there exists up to (n-1) cointegration relationships: $\beta Z_{t-k} \sim \mathrm{I}(0)$.

In this instance, $r \leq(n-1)$ cointegration vectors exist in $\beta$, that is, $r$ columns of $\beta$ form $r$ linearly dependent combinations of the variables in $Z_{t}$ each of which is stationary, together with (n-r) non stationary vectors (that is, $n-r$ columns of $\beta$ form I(1) common trends). Only the cointegration vectors in $\beta$ enter equation (11) above, otherwise $\Pi Z_{t-k}$ would not be $I(0)$, which implies that the last (n-r) columns of $\alpha$ are insignificantly small. Thus, the typical problem faced by determining how many, $\mathrm{r} \leq$ (n-1) cointegration vectors exist in $\beta$, amounts to equivalently testing which columns of $\alpha$ are zero. Consequently, testing for cointegration amounts to a consideration of the rank of $\Pi$, that is, finding the number of linearly independent columns in $\Pi$ (Harris 1995). If $\Pi$ has full rank such that there are $r=n$ linearly independent 
columns, then the variables in $Z_{t}$ are $\mathrm{I}(0)$, while if the rank of $\Pi$ is zero, then there are no cointegration relationships. If $\Pi$ has reduced rank, then there are $r \leq(n-1)$ cointegration vectors present. The results of the cointegration tests, obtained using MICROFIT 4.1 are also discussed in the next section.

\section{Estimation Results and Policy Implications}

In this section, we discuss the results of the estimation. The results were obtained using monthly monetary data on M1, M2, M3 and Reserve Money (RM) obtained from the Bank of Botswana, covering the period 2001-2007.

\section{Unit Root test results}

Table 1 and Table 2 in the Appendix present the results for the ADF and PP tests respectively. For stationarity, we expect the test statistic to be larger than the McKinnon critical values in absolute value and that they have a minus sign. The ADF test results show that the null hypothesis of unit root cannot be rejected for all the variables (in levels), using both the Constant and the Constant $\&$ Trend in the test equations except for the M1 money multiplier (k1). k1 is shown to be stationary (in levels), using both the Constant, and the Constant \& Trend in the test equation. The null hypothesis of unit root is however rejected for all the variables at $1 \%$. Although the results from the PP tests support the results from the ADF tests, the M3 money multiplier (k3) was shown to be stationary (in levels) at $1 \%$.

Since the variables are suspected not to be individually stationary in levels, but in first differences, we conclude that the variables are integrated of order one in levels, but integrated of order zero in first differences. When variables are suspected not to be individually stationary in levels, but in first differences, performing cointegration tests becomes theoretically possible (Diaz Bautista 2003).

\section{Cointegration test results}

Table 3 in the Appendix shows the trace and maximum eigenvalue statistics regarding the rank of $\Pi$, namely $r$. The tests involved testing the null hypothesis of no long run relationship, against the alternative that there is at least one cointegrating vector at $5 \%$ level of significance. The critical value for $r=0$ for the maximum eigenvalue statistic was given as 19.22 , and for $r=1$ it was given as 12.39 . For the trace statistic, the critical value at $5 \%$ level of significance for $r=0$ was given as 25.77 , while for $r=1$, it was given as 12.39 . The null hypothesis of no cointegrating relationship is reflected if the calculated statistic is greater than the critical value at $5 \%$ significance level, otherwise accept the null hypothesis. As indicated earlier, the objective of this paper is to test the stability of the multiplier process in Botswana. In terms of the objective of the paper therefore, accepting the null hypothesis of no long run relationship implies the money multiplier process is not stable, and therefore the concerned monetary aggregate cannot be used to anchor monetary policy. Rejecting the null hypothesis for $r=0$ on the other hand. implies that there is at least one cointegrating vector between the concerned monetary aggregates. Rejecting the null hypothesis for $r=0$, therefore implies that we test for $r=1$, in which case we are 
saying there is one cointegrating vector between the variables, and therefore a stable relationship would exist between the two variables. A stable relationship would then imply the concerned aggregate may be used to anchor monetary policy. Prior to this cointegration analysis however, the appropriate lag length of the VAR was determined using the Schwartz Bayesian Criterion. The Schwartz Bayesian Criterion suggested a lag order of 5 for the systems related to M1; lag order 4 for M2 and lag order 1 for M3.

The results of the cointegration (see Table 3) for the Maximum eigenvalue statistic for $r=0$ [18.59] indicates that we accept the null hypothesis of no long run relationship for narrow money (M1) at 5\% significance level. The Trace test statistic for $r=0$ [28.37] however suggests that we reject the null hypothesis at 5\% significance level. The trace statistic for $r=1$ [9.76] also suggests that we accept the null hypothesis of one cointegrating vector between narrow money and the reserve money, herein used as the monetary base. These results essentially imply that we cannot conclusively argue for a stable relationship for narrow money (M1), and therefore we cannot anchor monetary policy on M1. In the case of broad money (M2), there is evidence of a long run relationship using both the Maximum eigenvalue and the Trace test statistics. For $r=0$, the maximum eigenvalue statistic [23.85] suggests that we reject the null hypothesis of no long run relationship at 5\%. For $r=1$ [4.44], we accept the null hypothesis of one cointegrating vector, and therefore conclude that there is a stable relationship between broad money (M2) and reserve money. The results of the Trace test also suggest that we reject the null hypothesis for $r=0$ [28.29], and accept the null hypothesis for $r=1$ [4.44]. This stable relationship suggests that M2 money supply may be used to anchor monetary policy in Botswana. For M3, the maximum eigenvalue statistic and the trace statistic also suggest a stable relationship such that M3 money supply may also be used to anchor monetary policy. The maximum eigenvalue statistic for $r=0$ [33.58] implies that we reject the null hypothesis of no long run relationship, but accept the null hypothesis for $r=1$ [7.24]. The trace test statistic for $r=0$ [40.83] also suggests that we reject the null hypothesis, but accept the null for $r=1$ [7.25]. If the money supply is to be used as the target of policy, then the authorities must decide to which monetary aggregate between M2 and M3 they will accord primary importance. Although formal tests of convergence on M2 and M3 were not employed in the study, given that M3 consists of Bank of Botswana Certificates (which Bank of Botswana uses to mop up excess liquidity) held by Commercial banks, it seems reasonable to assume that M3 would be a better target of policy.

\section{Conclusion}

Monetary authorities in Botswana have over the years practiced monetary targeting, with domestic credit expansion (used as an indicator of demand conditions in the economy) being the primary target of monetary policy in order to achieve inflation objectives. While the inflation rate in Botswana has generally been stable and declining over the years, the Central Bank has often been failing to meet their annual inflation objectives, especially over the study period. As a result, the Bank has recently 
taken to announcing medium term inflation objectives instead of the annual inflation objectives. This paper, though not intended to test the efficacy of the existing strategy of controlling inflation, investigates whether M1, M2 or M3 monetary aggregates may also be used to anchor policy. This is achieved by employing stationarity and cointegration tests on these aggregates. The results of the estimation show a stable relationship for M2 and M3 monetary aggregates, suggesting that the two may be used to anchor policy. Although no formal convergence tests were applied to M2 and M3 monetary aggregates, with Bank of Botswana Certificates (held by commercial banks, and used by the Central Bank to mop up excess liquidity) classified under M3, it seems plausible that M3 will be a better target than M2. It is important to note however that the choice of a monetary aggregate as an anchor of policy does not depend only on the aggregates being stable, but also the trade ties especially for Botswana, where the majority of commodities, including food are imported from South Africa. This analysis however does not go as far as analysing the implications of using either of these two monetary aggregates under the existing trade ties and exchange rate arrangement.

\section{Appendix}

Figure 1. Inflationary trend in Botswana 2000-2007

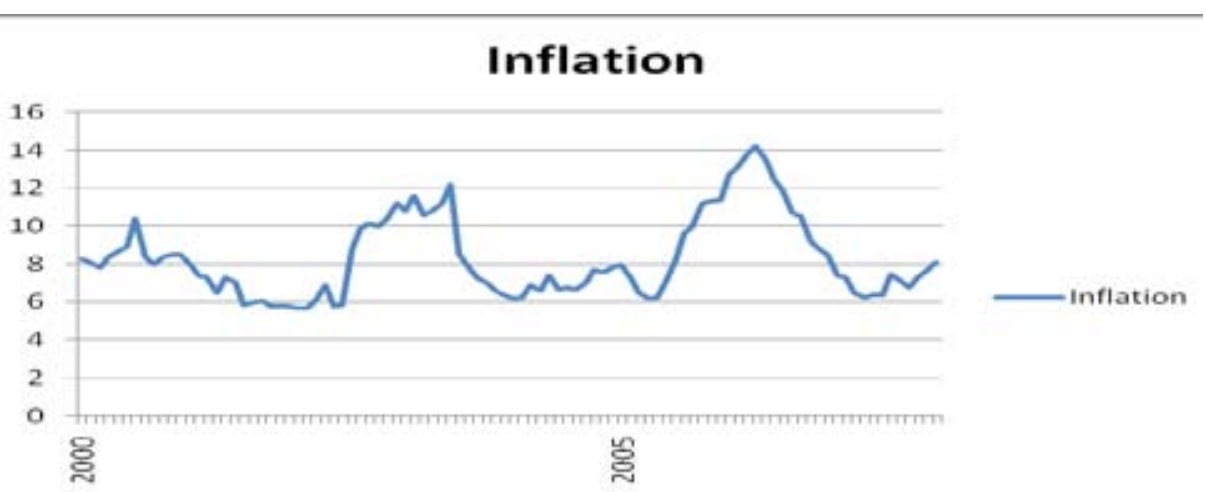

Source: author's caluculation using BoB data

Table 1: ADF Unit root test results

\begin{tabular}{|l|l|l|l|l|}
\hline & \multicolumn{2}{|c|}{$\begin{array}{l}\text { A D F } \\
\text { test(levels) }\end{array}$} & \multicolumn{2}{l|}{$\begin{array}{l}\text { ADF test }\left(1^{\text {st }}\right. \\
\text { differences })\end{array}$} \\
\hline & Constant & $\begin{array}{l}\text { Constant \& } \\
\text { Trend }\end{array}$ & Constant & $\begin{array}{l}\text { Constant \& } \\
\text { Trend }\end{array}$ \\
\hline Variable & & & & \\
\hline $\begin{array}{l}\text { Money Supply } \\
\text { (M1) }\end{array}$ & -0.115182 & -2.313963 & -7.184501 & -7.171813 \\
\hline $\begin{array}{l}\text { Money Supply } \\
\text { (M2) }\end{array}$ & 1.486527 & -0.664260 & -3.670829 & -4.047786 \\
\hline
\end{tabular}




\begin{tabular}{|c|c|c|c|c|}
\hline $\begin{array}{l}\text { Money Supply } \\
\text { (M3) }\end{array}$ & 1.493207 & -0.219000 & -4.437277 & -4.526192 \\
\hline Reserve Money & 0.321487 & -1.894942 & -7.301339 & -7.392905 \\
\hline $\begin{array}{l}\text { Money multiplier } \\
(\mathrm{k} 1)\end{array}$ & $-3.655745 * *$ & $-3.611060^{* *}$ & -7.293791 & -7.268563 \\
\hline $\begin{array}{l}\text { Money multiplier } \\
(\mathrm{k} 2)\end{array}$ & -1.342521 & -2.678248 & -6.960409 & -6.958927 \\
\hline $\begin{array}{l}\text { Money multiplier } \\
(\mathrm{k} 3)\end{array}$ & -3.192652 & -3.144764 & -7.447438 & -7.420557 \\
\hline
\end{tabular}

(**) implies significant at 5\%, otherwise significant at all levels

Table 2: PP Unit root tests

\begin{tabular}{|c|c|c|c|c|}
\hline & \multicolumn{2}{|c|}{ PP test(levels) } & \multicolumn{2}{|c|}{$\begin{array}{l}\text { PP test }\left(1^{\text {st }}\right. \\
\text { differences })\end{array}$} \\
\hline & Constant & $\begin{array}{l}\text { Constant \& } \\
\text { Trend }\end{array}$ & Constant & $\begin{array}{l}\text { Constant \& } \\
\text { Trend }\end{array}$ \\
\hline \multicolumn{5}{|l|}{ Variable } \\
\hline $\begin{array}{l}\text { Money Supply } \\
\text { (M1) }\end{array}$ & -0.427670 & -4.969631 & -14.62940 & -14.58265 \\
\hline $\begin{array}{l}\text { Money Supply } \\
\text { (M2) }\end{array}$ & 1.714582 & -0.694593 & -8.824937 & -9.263555 \\
\hline $\begin{array}{l}\text { Money Supply } \\
\text { (M3) }\end{array}$ & 0.980007 & -1.521644 & -11.00103 & -11.16490 \\
\hline Reserve Money & -0.232904 & -4.069342 & -14.48199 & -14.62355 \\
\hline $\begin{array}{l}\text { Money multiplier } \\
(\mathrm{k} 1)\end{array}$ & $-6.006614 *$ & $-6.041377^{*}$ & -14.16802 & -14.10776 \\
\hline $\begin{array}{l}\text { Money multiplier } \\
(\mathrm{k} 2)\end{array}$ & -2.626161 & -4.570662 & -14.14832 & -14.10092 \\
\hline $\begin{array}{l}\text { Money multiplier } \\
\text { (k3) }\end{array}$ & $-5.479680 *$ & $-5.453864 *$ & -14.43082 & -14.36370 \\
\hline
\end{tabular}

(*) implies significant at $1 \%$

The second step in our analysis therefore involved cointegration tests to test for the existence of long run relationships between the sub determinants of money multipliers i.e. M1, M2, M3 and RM.

\section{Table 3}

Cointegration LR Test Based on Maximal Eigenvalue of the Stochastic Matrix

$* * * * * * * * * * * * * * * * * * * * * * * * * * * * * * * * * * * * * * * * * * * * * * * * * * * * * * * * * * * * * * * * * * * * * * * *$

79 observations from 2001M6 to 2007M12. Order of VAR $=5$.

List of variables included in the cointegrating vector:

LOGM1 LOGRM Trend 
List of eigenvalues in descending order:

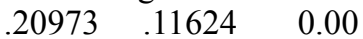

$* * * * * * * * * * * * * * * * * * * * * * * * * * * * * * * * * * * * * * * * * * * * * * * * * * * * * * * * * * * * * * * * * * * * * * * *$

Null Alternative Statistic 95\% Critical Value

$\begin{array}{llll}\mathrm{r}=0 & \mathrm{r}=1 & 18.5949 & 19.2200\end{array}$

$\mathrm{r}<=1 \quad \mathrm{r}=2 \quad 9.7617 \quad 12.3900$

$* * * * * * * * * * * * * * * * * * * * * * * * * * * * * * * * * * * * * * * * * * * * * * * * * * * * * * * * * * * * * * * * * * * * * * * *$

Use the above table to determine $\mathrm{r}$ (the number of cointegrating vectors).

Cointegration LR Test Based on Trace of the Stochastic Matrix

****************************************************************************

79 observations from 2001M6 to 2007M12. Order of VAR $=5$.

List of variables included in the cointegrating vector:

LOGM1 LOGRM Trend

List of eigenvalues in descending order:

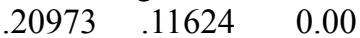

$* * * * * * * * * * * * * * * * * * * * * * * * * * * * * * * * * * * * * * * * * * * * * * * * * * * * * * * * * * * * * * * * * * * * * * * *$

Null Alternative Statistic 95\% Critical Value

$\mathrm{r}=0 \quad \mathrm{r}>=1 \quad 28.3565 \quad 25.7700$

$\mathrm{r}<=1 \quad \mathrm{r}=2 \quad 9.7617 \quad 12.3900$

****************************************************************************

Use the above table to determine $\mathrm{r}$ (the number of cointegrating vectors).

Cointegration LR Test Based on Maximal Eigenvalue of the Stochastic Matrix

$* * * * * * * * * * * * * * * * * * * * * * * * * * * * * * * * * * * * * * * * * * * * * * * * * * * * * * * * * * * * * * * * * * * * * * * * * *$

80 observations from 2001M5 to 2007M12. Order of VAR $=4$.

List of variables included in the cointegrating vector:

LOGM2 LOGRM Trend

List of eigenvalues in descending order:

$.25780 \quad .053971 \quad .0000$

******************************************************************************

Null Alternative Statistic 95\% Critical Value

$\mathrm{r}=0 \quad \mathrm{r}=1 \quad 23.8514 \quad 19.2200$

$\mathrm{r}<=1 \quad \mathrm{r}=2 \quad 4.4386 \quad 12.3900$

$* * * * * * * * * * * * * * * * * * * * * * * * * * * * * * * * * * * * * * * * * * * * * * * * * * * * * * * * * * * * * * * * * * * * * * * * *$

Use the above table to determine $r$ (the number of cointegrating vectors).

Cointegration LR Test Based on Trace of the Stochastic Matrix

$* * * * * * * * * * * * * * * * * * * * * * * * * * * * * * * * * * * * * * * * * * * * * * * * * * * * * * * * * * * * * * * * * * * * * * * *$

80 observations from 2001M5 to 2007M12. Order of VAR $=4$.

List of variables included in the cointegrating vector:

LOGM2 LOGRM Trend

List of eigenvalues in descending order:

$.25780 \quad 053971 \quad .0000$

$* * * * * * * * * * * * * * * * * * * * * * * * * * * * * * * * * * * * * * * * * * * * * * * * * * * * * * * * * * * * * * * * * * * * * * * * *$

Null Alternative Statistic 95\% Critical Value

$\mathrm{r}=0 \quad \mathrm{r}>=1 \quad 28.2900 \quad 25.7700$

$\mathrm{r}<=1 \quad \mathrm{r}=2 \quad 4.4386 \quad 12.3900$

*******************************************************************************

Use the above table to determine $\mathrm{r}$ (the number of cointegrating vectors).

Cointegration LR Test Based on Maximal Eigenvalue of the Stochastic Matrix

*****************************************************************************

83 observations from 2001M2 to 2007M12. Order of VAR $=1$.

List of variables included in the cointegrating vector:

LOGM3 LOGRM Trend

List of eigenvalues in descending order:

$.33275 \quad 083632 \quad 0.00$

****************************************************************************

$* * * * * *$

Null Alternative Statistic $95 \%$ Critical Value 


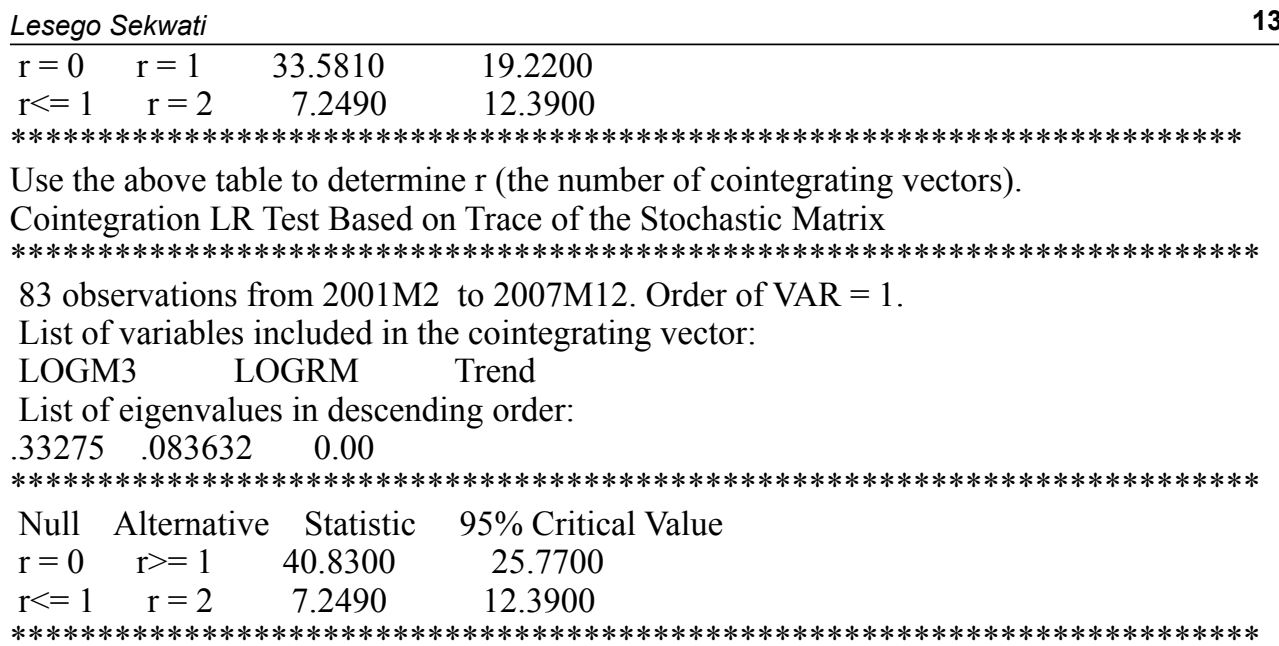

Use the above table to determine $\mathrm{r}$ (the number of cointegrating vectors).

\section{References}

Bank of Botswana, 2008, Monetary Policy Statement, Bank of Botswana, Gaborone.

Chakrabarti, S, 2006, Control of Inflation in Botswana. Botswana Journal of Economics. Vol 3, Issue 6. Pp 19-34

Diaz Bautista, A, 2003, Mexico's Industrial Engine of Growth: Cointegration and Causality. Revista Momento Economico, No. 120, pp 34-41.

Garfield, M.R and Thornton D.L, 1991, The Multiplier Approach to the Money Supply Process: A Precautionary Note. Federal Reserve Bank of St. Louis Review.

Gujarati, D.N, 2003. Basic Econometrics, ${ }^{\text {th }}$ ed. McGraw-Hill, New York

Harris, R.I.D, 1995. Using Cointegration Analysis in Econometric Modelling. Prentice Hall, Hertfordshire.

Korap, H.L, 2006. An Empirical Investigation Upon Money Multipliers and their Stability in the Turkish Economy for the post-1990 period, Discussion paper, Turkish Economic Association.

Mishkin F,S, 2000. From Monetary Targeting to Inflation Targeting: Lessons from the Industrialized Countries. Discussion paper

Pierce, D.G and Tysome, P.J, 1985. Monetary Economics: Theories, Evidence and Policy. Butterworths \& Co, Great Britain

Sahinbeyoglu, G, 1995. The Stability of Money Multiplier: A Test for Cointegration. Discussion paper, Central Bank of the Republic of Turkey, Research Department. Wooldridge, J.M, 2006. Introductory Econometrics, $3^{\text {rd }}$ ed. Thomson South-Western, USA 